Elaine Jeffreys and Jian XU (2017) 'Celebrity-inspired, Fan-driven: Doing Philanthropy through Social Media in Mainland China', Asian Studies Review. (DOI: http://dx.doi.org/10.1080/10357823.2017.1294145). Author Copy.

\title{
Celebrity-inspired, Fan-driven: Doing Philanthropy through Social Media in Mainland China
}

Elaine Jeffreys and $\mathrm{Xu}$ Jian

University of Technology Sydney

\begin{abstract}
This paper provides the first detailed study of the links between celebrity-fan communication networks and philanthropy in the People's Republic of China. It explains how the evolution of the Chinese Internet, and especially the rise of social media, has created new spaces in which fans of entertainment celebrities may be induced to engage with philanthropic causes. It then outlines the history of Chinese fan-driven philanthropic initiatives centred on people who became famous through reality-television popular music competitions. Finally, it offers a case study of the initiatives connected to popstar Li Yuchun, and examines the rationales provided by fans in online forums and interviews for their philanthropic engagement. Critics of celebrity-inspired philanthropy highlight its supposedly inauthentic and passive nature. Yet we find that fans actively exploit the forms of sociality that are provided by celebrity-fan communication networks, both to establish virtual participatory communities and to generate social action in the form of non-governmentorganised volunteering.
\end{abstract}

Keywords: celebrity, China, fans, government, media, philanthropy, volunteering

\section{Introduction}

This paper provides the first detailed study of the links between celebrity-fan communication networks and philanthropy in the People's Republic of China (PRC). Celebrity and fandom are growing subjects of academic inquiry in western contexts, as demonstrated by the launch 
Elaine Jeffreys and Jian XU (2017) 'Celebrity-inspired, Fan-driven: Doing Philanthropy through Social Media in Mainland China', Asian Studies Review. (DOI: http://dx.doi.org/10.1080/10357823.2017.1294145). Author Copy.

of dedicated journals such as Celebrity Studies (Taylor and Francis in 2010) and the Journal of Fandom Studies (Intellect Press in 2012). Contemporary studies of fandom eschew earlier accounts of fans as the 'ignorant, fanatical dupes' of commercial marketing and manipulative media representations (Coppa, 2013; Jenkins, 2006). Yet accounts of 'celanthropy', that is, 'charity projects fronted and, in the public mind, defined by celebrities', are generally negative (Rojek, 2014, p. 127). Ilan Kapoor (2013) criticises celanthropy as a depoliticising, capitalist 'humanitarian fantasy' that promotes social atomisation and turns citizens into passive spectators. It allegedly encourages fans to donate or purchase products for good causes, rather than becoming actively involved in collective efforts to improve the world we live in (Kapoor, 2013, pp. 42-4, 80-1; see also Rojek, 2014).

We qualify criticisms of celanthropy by examining the small-scale donating and volunteering activities associated with networked fan communities in mainland China. Philanthropy refers to the 'planned and structured giving of time, information, goods and services, voice and influence, as well as money, to improve the wellbeing of humanity and the community' (What we do: philanthropy, n.d.). Initial studies of the emergence of philanthropy in the PRC, following the country's post-1978 abandonment of socialist centralised planning and adoption of market economic reforms, often criticised individuals and organisations associated with the developing non-profit sector for being too embedded within the Communist Party-state system. The non-profit sector was seen as being insufficiently 'autonomous' or 'non-governmental' (Simon, 2013, pp. xxvii-xliii). Recent studies demonstrate that analyses based on a state/civil society divide tacitly prioritise the path of development that philanthropy and social activism has taken in western societies over alternative possible trajectories that it follows in countries such as China (Hoffman, 2016; Jeffreys, 2016, 2015). They focus instead on the new forms of sociality and social action that are being forged in in-between spaces that are neither 'of civil society' nor 'outside of the state' (Hoffman, 2016, p. 143). Such forms are produced through dynamic interactions between government efforts to promote volunteering, donating and celebrity-corporate philanthropy, and the actions of diverse organisations and individuals. Additionally, studies of Chinese web-based backpacking and translation communities highlight the capacity of social media to promote both leisure and small-scale social activism, by enabling young 
Elaine Jeffreys and Jian XU (2017) 'Celebrity-inspired, Fan-driven: Doing Philanthropy through Social Media in Mainland China', Asian Studies Review. (DOI: http://dx.doi.org/10.1080/10357823.2017.1294145). Author Copy.

people to seek networks and resources beyond the established spheres of state, family, school and work (Zhang, 2014; Zhang and Mao, 2013).

A search on Baidu.com and Google.cn using the keywords 'cishan' (charity/philanthropy), 'fensi' (fans) and 'jijin' (fund), revealed that a series of philanthropic initiatives have been created online since 2005 in the name of four Chinese reality-television-cum-popstars. Female singers Li Yuchun (b. 1984) and Ji Minjia (b. 1982), from Sichuan Province, came first and fifth place respectively in the 2005 finals of Super Girl (Chaoji nüsheng), a hugely popular talent contest broadcast on Hunan Satellite Television between 2004 and 2006 (Jian and Liu, 2009). Male singer Zhang Jie (b. 1982), also from Sichuan, won a 2004 Shanghaibased television competition called My Show (Woxingwoxiu). Zhang became a national idol in 2007 when he came fourth place in Super Boy (Kuaile Nansheng) - the male equivalent of Super Girl (Zhang Jie, n.d.). Male singer Jing Boran (b. 1989), from Liaoning Province, won first place on a 2007 Shanghai Dragon Television contest subtitled in English as My Hero (Jiayou! Hao nan'er). These singers are among the first cohort of mainland Chinese popstars to be domestically produced through interactive audience participation, and are representative of the broader GenY (born 1981-2000) turn to Chinese popular music culture that adapts western forms (Fung, 2013).

We collected news, posts and comments from online platforms associated with these philanthropic initiatives, noting their distinct digital footprints as based in both fan and government communication networks. These initiatives are not promoted through the celebrities' personal social media. Such promotion is undertaken by government-affiliated charities who advertise the celebrity endorsement and by people who self-identify as fans and advocate online in an informal capacity on behalf of such charities. Unlike in western societies, China-based celanthropy is typically linked to government rather than corporate and private interests. The reason is that charities in the PRC can only raise public funds if they are legally registered, and hence sponsored, and to some extent 'managed', by a government organisation (Jeffreys, 2015, p. 582). Fans of entertainment celebrities, who represent new types of youth-focused social groups in China, are thus being drawn into philanthropy-related policy agendas via a specific assemblage of commercial and government communication networks. 
Elaine Jeffreys and Jian XU (2017) 'Celebrity-inspired, Fan-driven: Doing Philanthropy through Social Media in Mainland China', Asian Studies Review. (DOI: http://dx.doi.org/10.1080/10357823.2017.1294145). Author Copy.

To further understand the motivations of fans who participate in celebrity-inspired philanthropy, we conducted nine semi-structured, online interviews with fans of Li Yuchun the star associated with China's most active fan-driven philanthropies to date. The interviews, each around 30-40 minutes in length, took place in January and February 2015. Respondents were found by following two dedicated forums for philanthropic activities associated with fans of Li Yuchun on Baidu. After examining forum posts and comments, we identified and contacted ten active users through the web services' internal messaging system. We sent them a common message introducing ourselves as researchers, our institutional affiliations and proposed research, and inviting them to participate in online interviews. Four people agreed to be interviewed through Chinese instant messaging, and mobile text and voice messaging services, and subsequently introduced us to the other respondents through their personal networks. Interviewees were advised that their responses might be used in research outputs, but any identifying features would remain confidential.

The paper proceeds by first explaining how the evolution of the Chinese Internet has created new spaces wherein fans of entertainment celebrities may be induced to engage with philanthropic causes. It then outlines the history of Chinese fan-driven philanthropies, looking at the defunct initiatives associated with Ji Minjia and Jing Boran and the ongoing but primarily donor-orientated initiatives connected to Zhang Jie. Finally, it offers a case study of the active philanthropic initiatives linked to Li Yuchun, which involve a fan-driven volunteering network.

An examination of fan-driven philanthropy in China challenges claims that the consumption of celebrity is an exploitative and alienating social practice that merely promotes the celebrity brand, and traps consumers in a loop of constant spectatorship (Kapoor, 2013; Rojek, 2014). Celebrity-inspired philanthropy does not necessarily imply 'celebrity-news junkies' in blankeyed isolation before their screens or even proxy social interaction. It produces virtual participatory communities without face-to-face interaction. More importantly, it creates volunteering communities that engage in offline activities and exist at 'one-step-removed' from government. 
Elaine Jeffreys and Jian XU (2017) 'Celebrity-inspired, Fan-driven: Doing Philanthropy through Social Media in Mainland China', Asian Studies Review. (DOI: http://dx.doi.org/10.1080/10357823.2017.1294145). Author Copy.

\section{Social media and celebrity-fan communication}

The rise of social media has created new types of celebrities such as reality-television-cumpopstars, and provided diverse spaces for publicists, celebrities and interested audiences to create and engage with celebrity content. Celebrities and their publicists now often use social media platforms to promote and protect the celebrity brand. They do so by providing 'fresh' celebrity news/images and countering gossip or scandal, and establishing the semblance of a direct relationship with their fans. 'Celebrity tweets', for example, are typically written in the first person, creating the impression that they are personal communications between celebrities and their followers. Such tweets are 'regularly cited in newspaper articles and blogs as “official” statements from the celebrity himself/herself” (Muntean and Petersen, 2009).

The expansion of celebrity-fan communication networks may be interpreted negatively as an inauthentic, exploitative extension of commercial mass culture marketing. That is, it can be viewed as:

voluntary cultural experiences produced at a distance by specialists for millions of people to share, in similar or identical form, at the same time or nearly so, with dependable frequency, creating a habitual audience around common needs and interests for profit. (Richard Ohmann cited in Coppa, 2014, p. 77)

This approach emphasises the larger economic contexts in which celebrity operates, but accords little agency to fans.

Alternatively, the expansion of celebrity-related communication may be interpreted as creating new spaces for networked activity that fans actively use and sometimes rework for their own social purposes. Henry Jenkins (2006) revises conceptualisations of fandom as the end-product of top-down, media marketing. He shows instead how fan engagement with consumer culture often creates a participatory culture wherein people value being members of a fan community, and feel some degree of social connection with one another, which can act as a springboard for peer-to-peer information sharing, informal mentorship and civic action. While not denying that fandom operates in commercial contexts, this approach draws attention to the multiple ways that fans engage with consumer culture and entertainment 
Elaine Jeffreys and Jian XU (2017) 'Celebrity-inspired, Fan-driven: Doing Philanthropy through Social Media in Mainland China', Asian Studies Review. (DOI: http://dx.doi.org/10.1080/10357823.2017.1294145). Author Copy.

media, and ultimately to the effects of involvement 'within participatory cultures of social media on the public orientation of young people' (Loader, Vromen and Xenos, 2014, p. 147).

The operation of celanthropy in western contexts is typically characterised according to the first view as manipulating fan affect or emotional investment in a one-sided (parasocial) relationship with a celebrity. Popstar Lady Gaga, for example, has over 61 million 'likes' on Facebook and 54 million followers on Twitter. Gaga/her management team famously use social media to promote the perception of a personalised relationship with her fans, whom she calls 'monsters'. Typical messaging includes statements such as: 'Happy New Year Monsters! I will love you for all of eternity’ (twitter.com/ladygaga, 1 January 2016). On World AIDS Day in 2010, Gaga and other celebrities threatened to deprive fans of their 'relationship', by staying off Facebook and Twitter until fans donated a total of USD 1 million to assist AIDS-affected families in Africa and India (Bhargava, 2010). The funds were raised, albeit more slowly than the campaign organisers had anticipated.

But the operation of fan-driven philanthropy in China demonstrates that celanthropy can encourage participatory and public-orientated youth cultures. We refer to forms of philanthropy that are ostensibly created and driven by fans, rather than the recent growth in celebrity-funded foundations (Jeffreys, 2015, pp. 582-4). We describe these initiatives as 'ostensibly' fan-created because it is not possible to verify the identities of the creators and users of the online fan networks that we discuss. Users are active in forums that do not use real-name identification systems and an individual may have multiple pseudonyms. Hence, some of the initiatives we discuss may have been created by celebrity media strategists masquerading as independent fans and subsequently developed a fan-driven momentum. Such celebrity-boosting practices are rumoured to be common in China and Korea, especially in relation to young pop singers (Zhang Jie "juankuanmen" bao fensi tuan heimu, 2012). They may also have been created by staff of government-affiliated charities experimenting with fundraising by collaborating with celebrities and using online donation (Liu, 2012). Whether or not these initiatives are authentic, their success depends on the perception that they are fan-owned. A more fruitful line of inquiry than questions of authenticity is therefore how these initiatives operate and elicit support in practice. 
Elaine Jeffreys and Jian XU (2017) 'Celebrity-inspired, Fan-driven: Doing Philanthropy through Social Media in Mainland China', Asian Studies Review. (DOI: http://dx.doi.org/10.1080/10357823.2017.1294145). Author Copy.

Communication about celebrities is a major component of online activities in the PRC, home of the world's largest online population with more than 668 million registered users in 2015. China's Internet users are predominantly young, educated and urban-based. More than 80 per cent are under 40 years old, nearly 88 per cent have at least a secondary education, 72 per cent live in cities, and 25 per cent are students (China Internet Network Information Centre, 2015). Most users have published or replied to posts, with 70 per cent wanting to 'discuss matters of common interest' with others, which includes entertainment news (Jin, 2009).

Commercial media services such as online forums, blogs, microblogs and instant messaging groups provide the main communication platforms. China had 120 million online forum users and more than 470 million bloggers in 2015 (China Internet Network Information Center, 2015). Such forums host diverse fan clubs and communities where registered users can view and comment on entertainment news via posted and private messages. Some are hosted on the official websites of celebrities as run by management teams, for example, actor Zhang Ziyi's website (helloziyi.com), while others refer to fan-created forums for singers such as $\mathrm{Li}$ Yuchun (http://tieba.baidu.com/f?kw=李宇春).

In December 2003, Baidu established Tieba (literally Postbar), a user-driven online discussion forum that hosts the majority of Chinese fan forums (tieba.baidu.com). Tieba allows users to search for and create a forum by typing a keyword into the Baidu search engine. Users can create a forum if that search generates no results, which is open to view by all Tieba users. Users can post anonymously or by using an account name. Posts may include one image or video. There were more than 19 million of these postbars by early 2016, mostly created by young consumers of popular cultural products.

Established in August 2009, Sina Weibo - the so-called 'Twitter of the East' - is another major online platform for fan communities. Sina Weibo had over 500 million registered users and nearly 220 million active users in 2015 (Incitez China, 2015). Its popularity is attributed in part to the Sina Corporation's strategy of leveraging more than 60,000 'real-name-verified celebrities', comprising entertainment and sports stars, corporate figures, government officials, and other VIPs, who dominate Weibo's communication structures (China socialmedia-marketing-with-weibo-and-twitter, 2011; Wang, She and Chen, 2014, p. 182). Studies 
Elaine Jeffreys and Jian XU (2017) 'Celebrity-inspired, Fan-driven: Doing Philanthropy through Social Media in Mainland China', Asian Studies Review. (DOI: http://dx.doi.org/10.1080/10357823.2017.1294145). Author Copy.

of the behaviour of Weibo users suggest that the majority (75 per cent) follow 'real-life friends', followed by 'school friends' (73 per cent), 'work colleagues' (52 per cent), 'celebrities' (51 per cent), 'family members and relatives' (49 per cent), 'teachers and work leaders' (37 per cent), and 'Internet friends' (30 per cent) (China Internet Network Information Center, 2014). Hence, around 250 million people follow celebritised personas on microblogging sites.

Tieba and Weibo, together with major blogging sites such as Sina, Qzone, Sohu and Netease, and instant messaging groups such as Tencent QQ group, constitute the main virtual space for fan communication. Blogging sites leverage celebrity blogs to attract 'ordinary' bloggers and readers, and offer more interactive platforms than official celebrity websites, although many such communities have since shifted to Weibo. Communication between fans on Tieba and Weibo is facilitated by Tencent QQ, which had more than 843 million monthly active users in mid-2015, and allows QQ users to establish small QQ groups for closed discussion (Tencent, 2015). QQ fan groups, usually based on geographic location, are posted on Tieba, blogs and Weibo to recruit fans to join virtual communities, which also facilitate philanthropy. These communities have not been displaced by the rise in 2015 of WeChat, a free messaging and calling app, because fans as individuals and groups have established QQ accounts and networks. Moreover, WeChat is usually used to communicate with family and colleagues using 'real' names, rather than to communicate with 'strangers' using pseudonyms.

The rise of social media in China has thus created diverse spaces for communication about celebrities to interested audiences, and between members of fan communities, and some of this communication now focuses on philanthropy. The next section outlines the history of China's fan-driven philanthropies. It highlights the integral role of social media platforms in their organisational structure and practices. It also shows how celebrity has been leveraged to encourage proxy social action in the form of charitable donations from fans.

\section{Social media and fan-driven charities}

Fan-driven philanthropies emerged in China in 2005, the year that online or 'e-giving' tookoff in the PRC (Alibaba and Rencede, 2013, p. 3). E-giving is generally touted as a low-cost, 
Elaine Jeffreys and Jian XU (2017) 'Celebrity-inspired, Fan-driven: Doing Philanthropy through Social Media in Mainland China', Asian Studies Review. (DOI: http://dx.doi.org/10.1080/10357823.2017.1294145). Author Copy.

secure and convenient platform that enables charities to show donors and potential donors the value of their work, and solicit support from communities networked through social media (see eGiving.com). These communities may be 'actual' as in sports and church-based groups, or 'virtual' as in mediated exclusively through the Internet. Leveraging the celebrity-fan relationship is one way of promoting e-giving.

A series of philanthropic initiatives were established from 2005 onwards to support government-affiliated charities in the name of four competitors on Chinese reality-television singing contests. The competitors are 'ordinary' people catapulted into short-lived or lasting fame through media publicity, and the exploitation of fan and critic affect via serial judgingvoting routines. Such routines claim to verify a competitor's talent and hence status as a 'wannabe' or publicly discovered 'star'. They turn on the investment of interested audiences in creating or boosting a celebrity. The 2005 finals of Super Girl, in particular, became a major cultural phenomenon, with 400 million people watching the final (Yang, 2009, p. 539), and fans casting more than 8 million mobile text votes (Yardley, 2005). Audience involvement in these competitions also extended to boosting the public reputation of certain competitors via philanthropy.

The Ji Minjia Education Fund (Ji Minjia zhuxue jijin) was founded ostensibly by fans on 16 August 2005 to improve Ji Minjia's chances of winning the 15 July-26 August finals of Super Girl (Jiamiyouaixin, 2005). A Tieba forum titled 'Ji Minjia' was opened on 11 June 2005 with a post calling for fans to help her win a regional contest and enter the national finals by sending SMS votes $(222.43 .34,2005)$. Regional Ji Minjia fan clubs were subsequently developed through Tieba and QQ. By mid-August, posts urged fellow fans to enhance Ji's reputation by donating to the Ji Minjia Education Fund and supporting Project Hope, an initiative run by the China Youth Development Foundation that helps impoverished youth to go to school (Jiamiyouaixin, 2005). The Fund raised CNY 16,000 by 26 October 2005 (Huaijiulaonanren, 2005). It then ceased to operate as Ji Minjia's popularity faded (Laoshuyeaijia, 2008). Neither the fund nor Ji's ambassadorial activities for Project Hope in 2012-2013 are mentioned on Ji Minjia's Weibo account, which had just over one million followers in 2016 (http://weibo.com/jiminjia11; Zhang, 2012). 
Elaine Jeffreys and Jian XU (2017) 'Celebrity-inspired, Fan-driven: Doing Philanthropy through Social Media in Mainland China', Asian Studies Review. (DOI: http://dx.doi.org/10.1080/10357823.2017.1294145). Author Copy.

Also now defunct, the BBF Charity Fund (BBF Aixin jijin) and the Jing Boran BBF Volunteer Corps (Jing Boran BBF zhiyuanfuwudui) were founded in April 2009 by fans of Jing Boran to celebrate his twentieth birthday. Fans of Jing Boran, who is known for his baby-faced good looks, call themselves 'BBF' - an acronym for 'Baby Fans', 'Be Boran's Fan', 'Be Boran's Friend', 'Be Boran's Family' and 'Bright Beautiful Future' (Fensi yanzhong Jing Boran, 2011). Fans celebrated Jing's birthday by calling for donations to the Liaoning Chapter of the Red Cross Society of China. This resulted in donations totalling CNY 10,000 and the Jing Boran Volunteer Corps was established shortly afterwards (Yong, 2009).

As with Ji Minjia, posts on Tieba proclaimed that fan participation in these initiatives would enhance Jing Boran's celebrity and reputation, revealing how fans are imbricated through social media in celebrity-boosting processes, whether at their own or others behest. In the words of one fan: 'charity is the responsibility of the Jing Boran Volunteer Corps and a vehicle for promoting Jing Boran (JingboranBBFjijin, 2009). Another fan explained their feelings at the launch of the BBF Charity Fund as follows:

I felt incomparable emotion and pride... we are proud to have transformed our love for Jing Boran into love for society, and proud that our beloved boy has obtained praise and recognition from the public. (Wangyinaijing_dada, 2009)

Apart from mention of funds donated to the Ya'an earthquake disaster-relief efforts in April 2013, however, there are limited posts and no contact details provided on Tieba or QQ for either the BBF fund or volunteers corps. Moreover, neither initiative has an official website. There is also no mention of a charity fund or volunteer group founded in his name on Jing Boran's Weibo, which had more than 17 million followers in 2016 (http://www.weibo.com/boranjing).

In contrast, Zhang Jie is associated with multiple and ongoing philanthropic initiatives. The Zhang Jie Big Dipper Volunteers' Charity (Zhang Jie beidouxingkong zhiyuan cishanhui) was established ostensibly by fans on 18 August 2007 to boost his public image after he failed to obtain a place in the Super Boy final. It was placed under the official management of the Red Cross Society of Sichuan Province on 10 October 2007 (Diandian xingguang, 2008), 
Elaine Jeffreys and Jian XU (2017) 'Celebrity-inspired, Fan-driven: Doing Philanthropy through Social Media in Mainland China', Asian Studies Review. (DOI: http://dx.doi.org/10.1080/10357823.2017.1294145). Author Copy.

making it the second legally registered fan charity in China after the Li Yuchun Fan Charity Fund (see below). The charity is named after Zhang's hit song 'Big Dipper Love', which he sang in the 2004 finals of My Show. It has a dedicated Sinablog page with information about its activities, including links to a Tieba forum, QQ groups, and blogs on Sohu and Netease, and 16 volunteering groups comprising around 300 volunteers (http://blog.sina.com.cn/hearjason; Zhangjie beidouxingkong zhiyuan cishanhui, 2015).

In April 2010, Zhang Jie and his fans made headlines by supporting the Yushu-Qinghai earthquake disaster-relief efforts coordinated by the China Foundation for Poverty Alleviation (CFPA). Zhang donated CNY 100,000 to the CFPA's 'Care Package' project, an initiative launched in 2009 which uses short-term celebrity ambassadors to solicit donations online, or through China Post, for the purchase of parcels for disaster-affected and impoverished young people. Student 'stationary', 'sports' and 'relief' packages, which cost between CNY 100-1,000, are sent with stamped-addressed postcards so that recipients can convey their thanks to donors. Although Zhang was not an official CFPA ambassador, news of his donation was followed by posts on Tieba and Weibo calling for fans to go to their local post offices on 8-9 May 2010 and send a package. This resulted in donations amounting to CNY 60,000 (Jin 80 ge, 2011).

Between 2010 and 2012, Zhang Jie's name was associated with two different philanthropic initiatives. In May 2010, the Zhang Jie Big Dipper Volunteers' Charity established the Big Dipper Fund (Beidouxingkong aixin jijinhui), under the auspices of the CFPA. The fund's operating slogan, which is promoted on the CFPA website, Weibo, Tieba, and relevant Sinablog pages, is: 'We are all together on the journey of love under the starry skies of the Big Dipper. Come join us! Donate CNY 10 a month and let the stars twinkle in the sky of love!' (Beikong jijin, 2011). In July 2012, Zhang Jie donated CNY 2 million to the fund, which was relocated under the auspices of the China Population Welfare Foundation (CPWF) (Beidouxingkong aijijinhui, 2012). The CPWF has directed these funds to the 'Zhang Jie Music Dream Classroom' (Zhangjie yinyue mengxiang jiaoshi), purchasing musical instruments for 27 schools by late 2014 (Zhang Jie yinyue mengxiang jiaoshi, 2015). 
Elaine Jeffreys and Jian XU (2017) 'Celebrity-inspired, Fan-driven: Doing Philanthropy through Social Media in Mainland China', Asian Studies Review. (DOI: http://dx.doi.org/10.1080/10357823.2017.1294145). Author Copy.

The charitable initiatives associated with Zhang Jie are thus driven by government-affiliated charities, which solicit donations from fans by leveraging Zhang's celebrity endorsement and philanthropic example. Although the Big Dipper Volunteers' Charity posted irregular donor lists on its blog between 2007-11, especially around the time of the 2008 Sichuan and 2010 Qinghai earthquakes, it was last updated on 17 March 2011 and the platform has since moved to Weibo. Zhang Jie had more than 33 million followers on Weibo in 2016. (www.weibo.com/jasonzhangjie), but the only donor list posted on the Weibo of the Big Dipper Fund, which had around 75,700 followers, was a list of people who donated to the CPWF on Zhang Jie's birthday in December 2014 (www.weibo.com/jasonzjlove, posted 20 December 2014).

The mobilisation of fans for reality-television voting therefore created communication networks that have since been used to stimulate donations for government-affiliated charities, whether originally organised by fans, celebrity management teams or the charities in question. The initiatives linked to Ji Minji and Jing Boran proved to be short-lived. Their short-term nature is presumably related to Ji's fading celebrity and lack of sustained input from Jing, his management team or a charity, and his lesser celebrity status when compared to that of Zhang Jie and Li Yuchun.

While Zhang Jie is connected to multiple, ongoing initiatives, they mainly function to solicit donations for charities by publicising Zhang Jie's endorsement and donation history, thereby encouraging fans to follow his example and enhancing the celebrity brand. Regional fan clubs promoted volunteering activities and the purchase of relief packages, chiefly in the context of major natural disasters. Hence, the philanthropic initiatives associated with Zhang Jie largely encourage proxy social action or what is negatively termed 'slacktivism'. This term refers to actions that are performed through the Internet in support of a social or political cause but are viewed as requiring little time or involvement.

In contrast, as discussed below, the celebrity-fan communication networks associated with $\mathrm{Li}$ Yuchun are used to encourage online donations and offline volunteering. Volunteering activities are organised by fans through social media demonstrating that virtual networks can create both community without face-to-face interaction and community engagement. 
Elaine Jeffreys and Jian XU (2017) 'Celebrity-inspired, Fan-driven: Doing Philanthropy through Social Media in Mainland China', Asian Studies Review. (DOI: http://dx.doi.org/10.1080/10357823.2017.1294145). Author Copy.

\section{Li Yuchun fan charity fund}

The most successful fan-driven philanthropies in China to date are the Li Yuchun Fan Charity Fund (Yumi aixin jijin) and the Li Yuchun Fan Volunteers (Yumi yigong), founded in 2006 and 2007 respectively. Li Yuchun fans collectively identify themselves as 'Yumi' (fans ' $m i$ ' of ' $Y u$ ', i.e., Li $Y u$ chun). Their active provision of 'free labour' to China's commercial entertainment industry by voting for Li Yuchun in music competitions and rankings, organising fan clubs, attending over-priced concerts, distributing promotional materials, encouraging local CD sales, and uploading videos and images on social media, is well documented (Fung, 2013; Yang, 2009). The voluntary participation of Li's predominantly female fan base in such labour is generally explained in terms of a fantasy of collective female empowerment. Fans have a shared investment in creating a domestic realitytelevision-popstar and turning her into an international megastar, which they view as a 'labour of love' (Yang 2009). Fan admiration for Li Yuchun is attributed to her perceived flaunting of stereotypical Chinese femininity, as expressed through the wearing of short hairstyles and 'boyish' clothing, and the singing of songs that express confidence, resilience and the ability to live independently of men (Fung, 2013; Yang and Bao, 2012). The decadelong involvement of Li Yuchun fans in public-orientated activities such as donating and volunteering has received limited attention in comparison, other than to claim that fan philanthropy offers Li Yuchun 'free' and 'continuous positive media coverage' (Yang, 2009, p. 532).

Shortly after she won the Super Girl final, Li Yuchun became a 'Love Angel' for a Chinese Red Cross Foundation (CRCF) initiative called 'One million activities to save child leukaemia sufferers' (Liu Xiang he Li Yuchun, 2005). On 19 March 2006, the CRCF launched a publicity campaign headed by Li to promote that initiative. The Li Yuchun Fan Charity Fund was established by fans the same day, as a sub-fund of the CRCF's 'Little Angel Fund', to boost Li's post-Super Girl career by supporting her ambassadorial activities (Yumi aixin jijin jianjie, 2008). 
Elaine Jeffreys and Jian XU (2017) 'Celebrity-inspired, Fan-driven: Doing Philanthropy through Social Media in Mainland China', Asian Studies Review. (DOI: http://dx.doi.org/10.1080/10357823.2017.1294145). Author Copy.

In April 2007, the Li Yuchun Fan Charity Fund became an independent fund under the management of the CRCF, which was described as 'fan-created' during its launch at a prestigious PRC government venue. To cite the CRCF Secretary General:

The Li Yuchun Fan Charity Fund is a public service innovation created by fans of Li Yuchun with the Chinese Red Cross Foundation. Regulations require dedicated funds (duanxiang jijin) to have CNY 1 million in start-up funds, but the Li Yuchun Fan Charity Fund is a penniless empty shell. The CRCF has decided to back this penniless fund because we believe Li Yuchun has influence, we believe in the power of the Internet, and we believe even more in the power of $\mathrm{Li}$ Yuchun's fans. Fans of Li Yuchun created this fund and those who are fortunate to be in the Great Hall of the People today bear witness to its establishment (Wang, 2007).

The CRCF's faith in the cause-marketing potential of the Li Yuchun brand proved to be well placed. Media coverage of the fund's establishment caused the charity's website to crash under heavy traffic as fans rushed to donate online (Wang, 2007). The CRCF subsequently appointed Li Yunchun as the fund's lifelong image ambassador in October 2007 (Yumi jijin, 2007).

The CRCF's successful leverage of celebrity-fan communication networks to solicit donations contradicts accounts of the perceived 'conflictual' relationship between China's governing authorities and Super Girl fandom, the former being posited as somewhat 'afraid' of self-mobilised, youth popular culture (Fung, 2013, pp. 82-83). The fund's donor demographics are consistent with the patterns of e-giving in China, based on a report commissioned by Alibaba, an e-commerce company. Apart from demonstrating commercial interest in cause marketing, the report indicates that 96 per cent of online donors are under 46 years old and nearly 77 per cent are younger than 36 years (Alibaba and Rencede, 2013, p. 4). Most donors (around 50 per cent) donate CNY 30 or under. Their main causes, in keeping with policy directives outlined in the PRC government's Five-Year Plans for National and Economic Social Development for 2001-15, are education, aged care, medical assistance, and support for the disabled (Alibaba and Rencede, 2013, p. 4; Jeffreys, 2015, p. 584). Reflecting these patterns, Li Yuchun fans are predominantly women aged under 40 (Xiong, 
Elaine Jeffreys and Jian XU (2017) 'Celebrity-inspired, Fan-driven: Doing Philanthropy through Social Media in Mainland China', Asian Studies Review. (DOI: http://dx.doi.org/10.1080/10357823.2017.1294145). Author Copy.

2013). The Li Yuchun Fan Charity Fund provides medical and other assistance to children, and donors usually give CNY 3-30 (see below).

The fund is endorsed by Li Yuchun - a celebrity whose fame is linked to social media and public 'voting' regimes. Li won the Super Girl final in 2005 by attracting more than 3 million mobile phone votes (Fung, 2013, p. 83). In 2013, she won the MTV-EMA Worldwide Act, an annual music award, beating other nominees, such as Justin Bieber, with over 100 million online votes $(\mathrm{Li}, 2013)$. Li thus has a large fan base comprised of technology-literate youth, many of whom can be mobilised through digital networks to support the fund through small but regular donations. She is also the fund's largest donor to date, with early donations amounting to CNY 200,000 (Cui, 2008).

Highlighting the circuitous nature of celebrity-fan communication, the Li Yuchun Fan Charity Fund has an official theme song, '[We are] the same as you' (He ni yiyang), which was reportedly written for Li Yuchun by fans in 2007. The fund's operating slogan as coined by $\mathrm{Li}$ is: 'There is love, there is hope. Don't give up!' (You ai, 2012). Li Yuchun regularly performs the theme song at concerts. Roughly translated, its chorus reads as follows.

We are strong like you and pursue our dreams despite adversity. There is support even in tough times. We are good. We want to create a paradise on earth. This is a song of hope. We love like you. (He ni yiyang, n.d.)

One respondent described her reaction to hearing this song as follows:

I was deeply touched by the lyrics the first time I heard it. I wanted to be a caring person like Li Yuchun. Doing charity and volunteering is the best way to show my love for her. (Author interview, 11 February 2015)

Although the fund has an office in the CRCF's Beijing headquarters, it exists primarily on a dedicated site on the CRCF's website. The content of that site is determined by the CRCF. It does not have a forum for viewers to post comments and images (see Figure 1). The site provides standard information: an overview of the fund; contact details; annual reports; media releases; information about how to donate and track donations; lists of donors, with the donor's name typically being an online pseudonym; and lists of the children helped by the fund, and the nature of their medical condition and care. 
Elaine Jeffreys and Jian XU (2017) 'Celebrity-inspired, Fan-driven: Doing Philanthropy through Social Media in Mainland China', Asian Studies Review. (DOI: http://dx.doi.org/10.1080/10357823.2017.1294145). Author Copy.

\section{<Figure 1: Li Yuchun Fan Charity Fund Official Website NEAR HERE〉}

Source: Chinese Red Cross Foundation. Available at http://new.crcf.org.cn/html/corn.html\#, accessed 3 March 2016.

The fund is also popularised through a fan-driven platform on Baidu - the Li Yuchun Fan Charity Fund Postbar (http://tieba.baidu.com/f?kw=玉米爱心基金\&ie=utf-8). Established on 20 August 2007, the postbar had around 3,400 followers and 112,200 posts in 2015. Although Li Yuchun has 3.7 million Weibo followers on her personal account, Li/her management team do not use that account to promote either her celebrity or philanthropy. At the time of writing, it contained only 32 tweets, with the last update on April 2013.

The way that the postbar is set up means that anyone identifying her/himself as a fan can use it to stimulate donations from the interested fan community. All such donations therefore appear, at face value, to be self-initiated. For example, on 14 April 2010, a massive earthquake hit Yushu County in Qinghai Province. Posts were subsequently placed on the Li Yuchun Fan Charity Postbar urging 'fellow fans' to donate through the fund to help disaster-affected people. One such post stated:

Fellow fans of Li Yuchun, although the Li Yuchun Fan Charity Fund has already allocated funds, we must continue our charitable actions. Please continue donating through the fund to the Qinghai earthquake [disaster-relief efforts]. Thank you (Bingyu, 2010).

Other posts provided a link to the fund's website and information about how to donate.

Respondents described the postbar as a fan-created and fan-driven product of the connections forged between fans of Li Yuchun as the original creators of her celebrity. As one interviewee explained:

Although the postbar is not the official website of the Li Yuchun Fan Charity Fund, it has authority among fans. Fans of Li Yuchun have a special connection with Tieba as the place where we first united to support her during the 2005 [Super Girl] competition. Because the Li Yuchun Postbar gets flooded by thousands of posts every day, posts about the Li Yuchun Fan Charity Fund sink 
Elaine Jeffreys and Jian XU (2017) 'Celebrity-inspired, Fan-driven: Doing Philanthropy through Social Media in Mainland China', Asian Studies Review. (DOI: http://dx.doi.org/10.1080/10357823.2017.1294145). Author Copy.

quickly. We therefore established a dedicated postbar for the fund for those who want to know more about it, and discuss and participate in its activities. The $L i$ Yuchun Fan Charity Fund Postbar is a voluntary community, independent from the CRCF and the management company of Li Yuchun. We just wanted to create a home for those who want to show their love for Li Yuchun through philanthropy and share their experience of doing philanthropy. We often post updates from the official website of the Li Yuchun Fan Charity Fund to the Postbar. We provide the same information as the $[\mathrm{CRCF}]$ official site and so much more. Fans who are donors visit the Li Yuchun Fan Charity Fund Postbar far more often than the official site (Author interview, 1 February 2015, our emphasis).

This response also highlights the main rationale for fans to support Li Yuchun-endorsed philanthropy, which is to express love for the celebrity.

Other interview responses suggest that donations are prompted chiefly by an assumed emotional connection with $\mathrm{Li}$ Yuchun and requests from others, rather than strictly a concern for disadvantaged children. Fans also value the ease and convenience of e-giving. As one respondent explained:

Most fans of Li Yuchun prefer to make online or mobile donations because it is convenient and timesaving. ... I usually donate at least CNY 31 every year because Chunchun's [Li Yuchun's] birthday is on 10 March [3.10.year in the Chinese date system]. Some fans donate CNY 3.1 or 310. I donate around three times a year, on Li Yuchun's birthday and when I see advocacy posts on the Li Yuchun Fan Charity Fund Postbar. Making a donation is the best way to give Chunchun a birthday gift and show my love to her. (Author interview, 25 January 2015)

Another respondent said:

I just follow the instructions on the Li Yuchun Fan Charity Fund to send a text message to a certain number. I can choose to donate CNY 5, 10 or 15 every month. The donation is automatically debited from the account balance of my mobile phone. Although the donation is small, I feel satisfied that I am doing something for Chunchun every time I receive the text message confirming my monthly donation. Fans of Li Yuchun voted for Chunchun to win the national 
Elaine Jeffreys and Jian XU (2017) 'Celebrity-inspired, Fan-driven: Doing Philanthropy through Social Media in Mainland China', Asian Studies Review. (DOI: http://dx.doi.org/10.1080/10357823.2017.1294145). Author Copy.

competition in 2005 through mobile phone text messages. Donating through text message is the best way to pass on our love to her. (Author interview, 27

February 2015)

Analysis of the basic components of the Li Yuchun Fan Charity Fund shows that fans play an important philanthropic role through donating, but that role is largely linked to the parasocial celebrity-fan relationship rather than active citizen engagement. For example, the CRCF has an e-grants system, where individuals and organisations can download and submit application forms for assistance. The Li Yuchun Fan Charity Fund, however, does not have an independent system, and fans do not participate in the grant process (http://new.crcf.org.cn). As one respondent explained:

Although most donors to the fund are fans of Li Yuchun, it is beyond our capability to decide where our donations should go and whom we should help. Our responsibility is to donate money. It is the responsibility of the CRCF to allocate our donation. Some people use the Li Yuchun Fan Charity Fund Postbar to post for help. We usually suggest that they go to the official site of the CRCF to submit an application because it is difficult for fans to verify the reliability of their posts. More importantly, the money is not in our hands for us to distribute. (Author interview, 1 February 2015)

The preceding responses illustrate the proxy nature of the social action encouraged by celebrity-inspired donating, which turns on emotional investment in the celebrity rather than active involvement in decision-making about who to help (or not). But the success of $\mathrm{Li}$ Yuchun fan-driven philanthropy also turns on the translation of virtual fan communities into offline social action through volunteering, as we now explain.

\section{Li Yuchun fan volunteers}

Volunteering - defined by the PRC government as the not-for-profit giving of time, intellect, strength and skills to support public benefit activities and promote social harmony - is a new object of public policy in China. China's media dubbed 2008 the 'Year of Volunteering' because nearly 5 million people volunteered for the Beijing Olympic Games and Sichuan 
Elaine Jeffreys and Jian XU (2017) 'Celebrity-inspired, Fan-driven: Doing Philanthropy through Social Media in Mainland China', Asian Studies Review. (DOI: http://dx.doi.org/10.1080/10357823.2017.1294145). Author Copy.

earthquake disaster-relief efforts. By 2013, China had 40 million registered volunteers, contributing 690 million working hours (Yao Ming huo guoji zhiyuanzhe zuzhi niandu dajiang, 2014).

The newfound importance of volunteering in the PRC is confirmed in a document issued by the Ministry of Civil Affairs (2013), the 'China Social Services Volunteer Team Building Guidelines for 2013-2020'. It advocates expanding the number of registered volunteers to comprise 10 per cent of the population by 2020. Registered volunteer organisations are operated and mobilised by government departments and Communist Party committees through coordination with non-profit, business and community organisations (State of volunteerism in China 2011, 2011). They usually have explicit missions, hierarchical management structures, and specific requirements for recruiting and training volunteers, which restrict self-initiated volunteer networking.

Communication through social media is facilitating small-scale, informal volunteering activities that exist at 'one-step-removed' from government-organised charities, such as the Li Yuchun Fan Volunteers. The Li Yuchun Fan Volunteers is managed by fans through a dedicated Baidu postbar (Yumi yigong ba) and at least 80 regional QQ groups (Tieba gongyi, 2015). These groups engage in diverse volunteering activities, including donating blood, environmental and animal protection, and visiting orphanages and aged-care facilities.

Like the Li Yuchun Fan Charity Fund, the Li Yuchun Fan Volunteers is motivated by emotional investment in celebrity. As the volunteers' postbar explains, the Li Yuchun Fan Volunteers refers to people who love Li Yuchun and who would like to engage in volunteering (Yumi yigong xiangjie jieshao, 2011). There is no official organisational structure. Fans become Li Yuchun Fan Volunteers by setting up or joining a group of fans to participate in local volunteering activities. The philosophy is 'volunteering, free, relaxed and happy'.

While leveraging enjoyment, the Li Yuchun Fan Volunteers promote self-initiated community engagement. An 'introduction' pinned to the top of the postbar on 14 March 2011 explains in a 'question and answer' format how to organise volunteering. It provides an event 
Elaine Jeffreys and Jian XU (2017) 'Celebrity-inspired, Fan-driven: Doing Philanthropy through Social Media in Mainland China', Asian Studies Review. (DOI: http://dx.doi.org/10.1080/10357823.2017.1294145). Author Copy.

template for fans to advertise volunteering activities on the postbar and encourages volunteers to subsequently share their experiences online. The template asks for information such as: the name of the city where the event is occurring; date, type and location of the activity; name of organiser; number of volunteers required; QQ details and end-date for signing up; meeting place and estimated length of activity; and names of sponsors and items required to engage in the activity, where applicable.

One such activity involved a visit to a government-run orphanage, the Shenyang City Children's Welfare Institute, on 15 November 2014. A Tieba user placed a post on the postbar on 8 November using an event template (http://tieba.baidu.com/p/3397592369). Responses to the post reveal that interested parties signed up using the QQ group of the Shenyang Li Yuchun Fan Volunteers (Number: 131846 0442). On 16 November, a participant put up a post about the visit, providing 14 on-scene photographs, the names of participants, and a list of the gifts that volunteers had brought for the children, including fruit, crayons, comic books and underwear (http://tieba.baidu.com/p/3413137605). A visit by volunteers to a Shanghai-based aged care facility in June 2015 provides similar details (tieba.baidu.com/p/3413137605).

As a Li Yuchun fan explained, QQ facilitates the coordination and expansion of volunteering networks:

Tieba is a good place to advertise and search for volunteering activities because it is open to the public. However, most organisers prefer using QQ groups for signing up [baoming] and coordination purposes. Dedicated Li Yuchun Fan Volunteers' QQ groups are seen as the headquarters of local Li Yuchun Fan Volunteers. Using QQ groups to sign up people can bring new blood into local volunteer communities and help to build up networks between new and old volunteers through group chatting. When the registration process is completed, further notices of activities are usually released in QQ groups. (Author interview, 10 February 2015) 
Elaine Jeffreys and Jian XU (2017) 'Celebrity-inspired, Fan-driven: Doing Philanthropy through Social Media in Mainland China', Asian Studies Review. (DOI: http://dx.doi.org/10.1080/10357823.2017.1294145). Author Copy.

More importantly, she noted that the post-activity sharing of volunteer experiences recognises the work of the Li Yuchun Fan Volunteers, and promotes ongoing volunteering through regional or city-based fan competition. In her words:

Sharing on-scene photos shows people that we do what we say we do... We want people to see who participated in the activities, what we did and what was contributed because doing good deeds also needs recognition from others. ... Sharing what we do may also inspire volunteers in other cities to conduct volunteering actions, because fans of Li Yuchun in any region don't want to lag behind. (Author interview, 10 February 2015)

Until recently, figures for the total number of local volunteering activities conducted annually were posted at the top of the Li Yuchun Fan Volunteers' postbar (http://tieba.baidu.com/f?kz=332663721; http://tieba.baidu.com/f?kz=1016877961).

Fan volunteering activities are now publicised on a selective basis in the online Lee Weekly (leeweekly.com), produced by fans since May 2012. The Lee Weekly centres on news about Li Yuchun and secondarily on life-style, fashion and beauty advice. But it also has a 'Volunteer \& Charity Archive' (www.leeweekly.com/?cat=15), which presents selected activities from the Li Yuchun Fan Volunteers postbar, and messages posted on the CRCF website by donors to the Li Yuchun Fan Charity Fund.

Interview responses highlight the embeddedness of these self-initiated volunteering communities in communication networks that rely on the building of circuitous, affective networks between celebrities and fans. The main reasons provided by respondents for engaging in such volunteering were to follow Li Yuchun's example, express their love for Li and promote her public reputation. As one volunteer explained:

Chunchun is a very caring and excellent person. She often attends charitable activities, setting a great example for us. Our volunteering activities could make more people know about Chunchun and help maintain her positive public image. (Author interview, 10 February 2015)

Another respondent equated volunteering with promoting a positive image of both Li Yichun and $\mathrm{Li}$ Yuchun fans. In her words: 
Elaine Jeffreys and Jian XU (2017) 'Celebrity-inspired, Fan-driven: Doing Philanthropy through Social Media in Mainland China', Asian Studies Review. (DOI: http://dx.doi.org/10.1080/10357823.2017.1294145). Author Copy.

I still remember many media and people questioned Li Yuchun during the 2005 Super Girl competition. They criticised Chunchun's singing and predicted her popularity would be short-lived. Fans of Li Yuchun were also criticised as a group of crazy and irrational people who had helped her gain bubble fame. The truth is Chunchun is still popular after 10 years. Li Yuchun fans' charitable and volunteering actions have demonstrated that we are caring fans. We use our real actions to maintain Chunchun's public image and respond to the criticisms. (Author interview, 11 February 2015)

Put differently, Li Yuchun fans volunteer to demonstrate to the 'outside world' that their involvement in turning a reality-singing-competition contestant into a megastar is a rational and desirable form of social behaviour. 'Good' fan practice, and hence membership of an imagined 'ideal' Li Yuchun fan community, means promoting and mainstreaming Li Yuchun and Li Yuchun fandom. It requires fans to work at making Li Yuchun and Li Yuchun fans an accepted and valued part of Chinese society through participation in publicly endorsed activities such as volunteering.

Respondents also valued the convenient, fun and sociable nature of Li Yuchun Fan Volunteering. As one respondent explained:

I have full-time work and don't have much spare time. Li Yuchun Fan Volunteers' activities are always simple, flexible and fast. I last attended a blood donation activity. The other four fans even re-scheduled the original meet-up time to suit me. We gave blood and then had an enjoyable meal during my lunch break. (Author interview, 14 February 2015)

Another respondent said that being a Li Yuchun Fan Volunteer enabled her to engage in enjoyable volunteering activities, while socialising with like-minded people.

I attend volunteering activities for fun. I love taking care of children and getting to know new friends. I seldom miss the visit to my city's Children's Welfare Institute. I can play with children and meet more fans of Li Yuchun. (Author interview, 14 February 2015) 
Elaine Jeffreys and Jian XU (2017) 'Celebrity-inspired, Fan-driven: Doing Philanthropy through Social Media in Mainland China', Asian Studies Review. (DOI: http://dx.doi.org/10.1080/10357823.2017.1294145). Author Copy.

Yet another respondent stated: 'I feel very relaxed and happy when I do volunteering activities with other fans of Li Yuchun. I take the volunteering activities as opportunities to socialise with other fans' (Author interview, 13 February 2015).

Some fans said volunteering enhanced their skills, knowledge and careers. As one respondent explained: 'although I am an adult university student, my social experience is limited, being a volunteer allows me to better understand society ... and improve my communication skills' (Author interview, 10 February 2015). Another volunteer said: 'the textbook knowledge is not enough for me to survive in a competitive society; I need to enrich my experience ...' (Author interview, volunteer 3, 11 February 2015). Two respondents said that their motivation volunteering was to transform themselves by 'helping others and becoming a loving person' (Author interview, 11 February 2015).

These explanations replicate the standard rationales for youth volunteering in western countries, which is to meet people, make friends and have fun, and then to learn something and improve their career prospects, rather than altruism or to 'change the world' (The Case Foundation, 2006, p. 6; see also Zhang, 2014). This arguably demonstrates a lack of genuine civic engagement, however that may defined. But it also highlights new possibilities for interpersonal relationships, public association and even changing government-citizen relations in the PRC.

In summary, fan-driven philanthropies are embedded in networks that strengthen the circuits of communicative capitalism - consumerism, materialism, commercial entertainment and the cult of celebrity. Fan volunteering is based on the celebrity-enhancing incitement to demonstrate 'love' for Li Yuchun and encouraged by the potential to talk about Li Yuchun with other fans. It is further encouraged by the act of publicising volunteering activities and the post-activity sharing of volunteer experiences on celebrity-fan communication networks.

At the same time, fan-driven philanthropies create opportunities for individuals to help themselves and others through volunteering and associated skill enhancement. The $\mathrm{Li}$ Yuchun Fan Volunteers enable fans to socialize with people outside of the established community networks of family, school and work. It also creates opportunities for young 
Elaine Jeffreys and Jian XU (2017) 'Celebrity-inspired, Fan-driven: Doing Philanthropy through Social Media in Mainland China', Asian Studies Review. (DOI: http://dx.doi.org/10.1080/10357823.2017.1294145). Author Copy.

Chinese adults to engage with social issues in ways that are not necessarily pre-determined by government, even as they intersect with public policy and the activities of governmentaffiliated charities.

\section{Concluding remarks}

This paper has examined a series of fan-driven philanthropic initiatives created since the mid2000s in the name of four Chinese reality-television-cum-popstars. Some of these initiatives were short-lived, reflecting waning celebrity or lack of persistent input from an organised charity or celebrity team. Others are active but function chiefly to solicit donations. Yet others encourage both donating and volunteering.

An examination of philanthropy by Li Yuchun fans qualifies claims that the consumption of celebrity simply promotes the celebrity brand and traps consumers in a circuit of passive spectatorship. The circulation of affect through multiple media involving Li Yuchun produces virtual participatory communities and offline volunteering communities. Fans view these communities as independent or fan-organised rather than government-organised, even though they operate under the auspices of a government-affiliated charity. This finding warrants further studies of celebrity-fan communication, social media and cause marketing, and government-endorsed and new types of social organisation, in China.

Fan participation in this particular culture of celebrity-inspired philanthropy has obvious benefits for all of the parties concerned, despite its temporariness as linked to a specific star's fame. It popularises and provides support for government-affiliated charities, while drawing new forms of youth-focused social groups into public policy agendas. It promotes a positive public image of certain celebrities, while the charity- and fan-promoted nature of associated publicity protects the charity from celebrity scandal, and the celebrity from charity-corruption scandal. It also benefits fans as participants in celebrity-boosting and philanthropic initiatives. Participating fans enjoy the forms of sociality associated with celebrity consumption and fan communities. They may even experience the sense of pleasure and achievement that is associated with making friends, skill-enhancement and doing something, however 'small', to improve the world they live in. 
Elaine Jeffreys and Jian XU (2017) 'Celebrity-inspired, Fan-driven: Doing Philanthropy through Social Media in Mainland China', Asian Studies Review. (DOI: http://dx.doi.org/10.1080/10357823.2017.1294145). Author Copy.

The example of Li Yuchun-inspired philanthropy demonstrates that fans actively exploit the inauthentic forms of sociality provided by social media to create their own communication networks. These networks are used to promote personal interaction, broaden social ties and provide information about how individuals can become civically involved in ways that are not explicitly directed by government. Such participatory networks are unlikely to generate unified collective activism understood in oppositional political terms. Yet in supporting heterogeneous, small-scale connective actions, they make it possible for young networked people in China to be civically engaged at a local level and on their own terms. Conversely, if encouraging young adults to have a sense of public purpose is viewed as one of the many challenges facing the PRC government, then, leveraging celebrity and fandom appears to a new means of achieving that goal.

\section{Acknowledgements}

This research was supported under the Australian Research Council's Future Fellowship funding scheme (FT100100238) and the Australian Government, Department of Education, Endeavour Postdoctoral Fellow funding scheme.

\section{References}

222.43.34 (2005) Kuai gei Jiajia toupiao a, ta de hao shao [Quick! Vote for Ji Minjia, she has so few votes]. Tieba, 11 June. Available at http://tieba.baidu.com/p/19079311, accessed 3 March 2016.

Alibaba and Rencede (2013) Zhongguo wangluo juanzeng yanjiu baogao [Report on Chinese online donations]. Available at http://www.recende.com/Item/Show.asp?m=1\&d=1207, accessed 3 March 2016.

Beidouxingkong aijijinhui [The Big Dipper Fund] (2012) China Population Welfare Foundation, 25 June. Available at http://www.cpwf.org.cn/jg_bd/doc2.asp, accessed 28 July 2012. 
Elaine Jeffreys and Jian XU (2017) 'Celebrity-inspired, Fan-driven: Doing Philanthropy through Social Media in Mainland China', Asian Studies Review. (DOI: http://dx.doi.org/10.1080/10357823.2017.1294145). Author Copy.

Beikong jijin (2011) Beidouxingkong aixin jijin xieshou xingxingwei ai xing 11-12 yue juanzeng mingdan [Big Dipper Fund November-December donor list]. Sina.com, 28 January. Available at http://blog.sina.com.cn/s/blog_4dfd88d80100ny2i.html, accessed 3 March 2016.

Bhargava, Rohit (2010) Why the 'Digital Death' campaign failed despite celebrity support. Influential Marketing Blog, 6 December. Available at http://www.rohitbhargava.com/2010/12/why-the-digital-death-campaign-failed-despitecelebrity-support.html, accessed 3 March 2016.

Bingyu, Chunxue (2010) Yumiyigongba lianjie) yumiyigong haozhao quanti yumi dingxiang qinghai dizhen juankuan [Link from Li Yuchun Fan Volunteers Postbar: Li Yuchun Fan Volunteers appeal to fans of Li Yuchun to donate to the Qinghai earthquake]. Yumi aixin jijin $b a, 16$ April. Available at http://tieba.baidu.com/p/750175726?pid=17252825699\&cid=0\#17252825699, accessed 3 March 2016.

China Internet Network Information Center (2014) 2014 nian Zhongguo shejiaolei yingyong yonghu xingwei yanjiu baogao [2014 report on the behaviours of Chinese social media users]. Available at http://www.cnnic.cn/hlwfzyj/hlwxzbg/201408/P020140822379356612744.pdf, accessed 3 March 2016.

China Internet Network Information Center (2015) Statistical report on Internet development in China, July 2015. Available at http://cnnic.cn/hlwfzyj/hlwxzbg/hlwtjbg/201507/P020150723549500667087.pdf, accessed 3 March 2016.

China social-media-marketing-with-weibo-and-twitter - presentation transcript (2011) BlueCurrent Group Hong Kong, 25 July. Available at http://www.slideshare.net/BlueCurrentGroup/chinasocialmediamarketingwithweiboandtwitter, accessed 3 March 2016. 
Elaine Jeffreys and Jian XU (2017) 'Celebrity-inspired, Fan-driven: Doing Philanthropy through Social Media in Mainland China', Asian Studies Review. (DOI: http://dx.doi.org/10.1080/10357823.2017.1294145). Author Copy.

Coppa, Francesca (2014) Pop culture, fans and social media, in Jeremy Hunsinger and Theresa Senft (eds) The Social Media Handbook, pp. 76-92 (Abingdon: Routledge).

Cui, Yijia (2008) Yumi aixin jijin 2 zhounian Li Yuchun jiexiao biaozhi [Li Yuchun Fan Charity Fund is in its second year: Li Yuchun promotes the logo]. Sina, 22 March. Available at http://www.zhxww.net/zhnews400/zh1/zh06/200803/20080322101438.htm, accessed 3 March 2016.

Diandian xingguang, zhaoliang shijie-Beidouxingkong cishanhui 2007 dashiji (zhuanzai) [Starlight brightens the world: Chronicle of Zhang Jie Big Dipper Volunteers' Charity 2007 (repost)] (2008) 14 January. Available at http://bbs.tianya.cn/post-funstribe-139963-1.shtml, accessed 3 March 2016.

Fensi yanzhong Jing Boran: Qingfen nuli yong yanji gesheng zhengfu BBF [Jing Boran in the eyes of fans: Hardworking, fans conquered by his acting and singing] (2011) Fensiwang, 26 July. Available at http://bagua.ifensi.com/article-427645.html, accessed 3 March 2016.

Fung, Anthony (2013) Deliberating fandom and the new wave of Chinese pop: a case study of Chris Li. Popular Music 32, pp. 79-89.

He ni yiyang [The same as you] (n.d.) Tencent. Available at http://baike.soso.com/v6110.htm;\%20http://www.tudou.com/programs/view/Gac5pSz1u1k/\% 29, accessed 1 May 2015.

Hoffman, Lisa (2016) Serving and providing for those 'in need': 'intermediary' spaces and practices of liaising, collaborating and mobilizing in urban China, in David Bray and Elaine Jeffreys (eds) New Mentalities of Government in China, pp. 141-58 (Abingdon: Routledge).

Huaijiulaonanren (2005) Qinghua nüsheng zuo guanggao: Guanyu Ji Minjia gemi aixin jijinhui [Girls at Tsinghua University advertise the Ji Minjia charity fund]. Tieba, 16 November. Available at 
Elaine Jeffreys and Jian XU (2017) 'Celebrity-inspired, Fan-driven: Doing Philanthropy through Social Media in Mainland China', Asian Studies Review. (DOI: http://dx.doi.org/10.1080/10357823.2017.1294145). Author Copy.

http://tieba.baidu.com/p/66144958?pid=438457252\&cid=0\#438457252, accessed 3 March 2016.

Incitez China (2015) Weibo MAUs reached 222 million in Q3 2015. China Internet Watch, 20 November. Available at http://www.chinainternetwatch.com/15740/weibo-q32015/\#ixzz3uFriOvni, accessed 3 March 2016.

Jeffreys, Elaine (2015) Celebrity philanthropy in mainland China. Asian Studies Review, 39(4), pp. 571-88.

Jeffreys, Elaine (2016) Elite philanthropy in China and America: the disciplining and selfdisciplining of wealth, in David Bray and Elaine Jeffreys (eds) New Mentalities of Government in China, pp. 118-40 (Abingdon: Routledge).

Jenkins, Henry (2006) Fans, Bloggers, and Gamers: Exploring Participatory Culture (New York: New York University Press).

Jian, Miaoju and Chang-de Liu (2009)'Democratic entertainment', commodity and unpaid labor of reality TV: A preliminary analysis of China's Supergirl. Inter-Asia Cultural Studies 10(4), pp. 524-43.

Jiamiyouaixin (2005) Yong aixin ai Jiajia, wei Xiwang Gongcheng juankuan changyishu [Proposal: Show your love for Ji Minjia by donating to Project Hope]. Tieba, 16 August. Available at http://tieba.baidu.com/f?kz=31740783, accessed 3 March 2016.

Jin 80 ge baidu tieba bayou da youju juankuan aixin baoguo [Around 80 Baidu Tieba friends visit post office to donate Care Packages] (2011) China Foundation for Poverty Alleviation, 11 May. Available at http://baoguo.cfpa.org.cn/show.php?contentid=606, accessed 16 January 2012. 
Elaine Jeffreys and Jian XU (2017) 'Celebrity-inspired, Fan-driven: Doing Philanthropy through Social Media in Mainland China', Asian Studies Review. (DOI: http://dx.doi.org/10.1080/10357823.2017.1294145). Author Copy.

Jin, Liwen (2009) Chinese outline BBS sphere: What BBS has brought to China. Master's thesis, Massachusetts Institute of Technology, April. Available at http://cms.mit.edu/research/theses/LiwenJin2008.pdf, accessed 3 March 2016.

JingboranBBFjijin (2009) Ni zai women jiu zai, Jing Boran zhiyuanfuwudui shouqi yishi huodong zong [I am here because you are here, Jing Boran Volunteer Corps ceremony]. Tieba, 7 May. Available at http://tieba.baidu.com/f?kz=575037428, accessed 1 May 2015.

Kapoor, Ilan (2013) Celebrity Humanitarianism: The Ideology of Global Charity (Abingdon: Routledge).

Laoshuyeaijia (2008) Ruo ruo de wen yiju ... Ji Minjia aixin jijinhui xianzai hai you mei? [A pathetic question: Does the Ji Minjia charity still exist?]. Tieba, 16 May. Available at http://tieba.baidu.com/p/379920890?pid=3879092646\&cid=0\#3879092646, accessed 3 March 2016.

Li, Shen (2013) Chris Lee wins MTV EMA Worldwide Act. China.org.cn, 11 November. Available at http://www.china.org.cn/arts/2013-11/11/content_30560519.htm, accessed 5 June 2015.

Liu Xiang he Li Yuchun huo 'Aixin tianshi' chenghao [Liu Xiang and Li Yichun receive the title of 'Love Angel'] (2005) Xinhuanet.com, 29 December. Available at http://news.xinhuanet.com/photo/2005-12/29/content_3986032.htm, accessed 3 March 2016.

Liu, Xuanguo (2012) The development and innovation of fundraising models of the public foundations in China. Sina.com, 13 April. Available at http://blog.sina.com.cn/s/blog_5bf21dee01014ddy.html, accessed 3 March 2016.

Loader, Brian, Vromen, Ariadne, and Michael Xenos (2014) The networked young citizen: Social media, political participation and civic engagement. Information, Communication and Society 17(2), pp. 143-50. 
Elaine Jeffreys and Jian XU (2017) 'Celebrity-inspired, Fan-driven: Doing Philanthropy through Social Media in Mainland China', Asian Studies Review. (DOI: http://dx.doi.org/10.1080/10357823.2017.1294145). Author Copy.

Ministry of Civil Affairs of the PRC (2013) Zhongguo shehui fuwu zhiyuanzhe duiwu jianshe zhidao gangyao (2013-2020 nian) de tongzhi [China Social Services Volunteer Team Building Guidelines 2013-2020], 1 June. Available at http://www.mca.gov.cn/article/zwgk/fvfg/shgz/201401/20140100573025.shtml, accessed 3 March 2016.

Muntean, Nick and Anne Helen Petersen (2009) Celebrity Twitter: Strategies of intrusion and disclosure in the age of technoculture. M/C Journal 12(5), pp. 1-6.

Rojek, Chris (2014) "Big citizen” celanthropy and its discontents. International Journal of Cultural Studies 17(2), pp. 127-41.

Simon, Karla (2013) Civil Society in China (Oxford: Oxford University Press).

State of volunteerism in China 2011 - engaging people through ideas, innovation and inspiration (2011) United Nations Development Programme and United Nations Volunteers: Beijing.

Tencent (2015) Tencent announces 2015 second quarter and interim results, 12 August. Available at http://www.tencent.com/en-us/content/at/2015/attachments/20150812.pdf, accessed 3 March 2016.

The Case Foundation (2006) Citizens at the Center: A New Approach to Civic Engagement. Available at http://casefoundation.org/wp-content/uploads/2014/11/CitizensAtTheCenter.pdf, accessed 3 March 2016.

Tieba gongyi [Tieba charity] (2015) Baidu Baike. Available at http://baike.baidu.com/view/4434689.htm, accessed 3 March 2016.

Wang, Ning, She, James, and Chen, Junting (2014) How "big vs" dominate Chinese microblog: A comparison of verified and unverified users on sina weibo. Proceedings of the 2014 ACM conference on Web science, pp. 182-6. 
Elaine Jeffreys and Jian XU (2017) 'Celebrity-inspired, Fan-driven: Doing Philanthropy through Social Media in Mainland China', Asian Studies Review. (DOI: http://dx.doi.org/10.1080/10357823.2017.1294145). Author Copy.

Wang, Rupeng (2007) Yumi aixin jijin: Li Yuchun he Yumi gongtong chuanzaode qiji [The Li Yuchun Fan Charity Fund: The miracle created by Li Yuchun and her fans]. Sohu.com, 17 April. Available at http://wangrupengvip.blog.sohu.com/42331044.html, accessed 3 March 2016.

Wangyinaijing_dada (2009) Ni zai, women jiu zai [We're with you]. Tieba, 7 May. Available at http://tieba.baidu.com/p/575037428?pn=2, accessed 3 March 2016.

What we do: philanthropy (n.d.) Philanthropy Australia. Available at http://www.philanthropy.org.au/about-us/what-we-do/, accessed 3 March 2016.

Xiong, Yuan (2013) Yumi de qinian zhiyang [Li Yuchun fans's seven years of support]. Gemag.com, 6 March. Available at http://www.gemag.com.cn/9/31573_1.html, accessed 3 March 2016.

Yang, Ling (2009) All for love: The Corn fandom, prosumers, and the Chinese way of creating a superstar. International Journal of Cultural Studies 12(5), pp. 527-43.

Yang, Ling and Bao, Hongwei (2012) Queerly intimate: Friends, fans and affective communication in a Super Girl fan fiction community. Cultural Studies, 26(6), pp. 842-71.

Yao Ming huo guoji zhiyuanzhe zuzhi niandu dajiang [Yao Ming receives award from international volunteer organisation] (2014) Хinhua, 23 October. Available at http://news.xinhuanet.com/world/2014-10/23/c_1112950913.htm, accessed 3 March 2016.

Yardley, Jim (2005) The Chinese get the vote, if only for Super Girl. New York Times, 4 September. Available at http://www.nytimes.com/2005/09/04/weekinreview/the-chinese-getthe-vote-if-only-for-super-girl.html?_r=0, accessed 19 February 2016. 
Elaine Jeffreys and Jian XU (2017) 'Celebrity-inspired, Fan-driven: Doing Philanthropy through Social Media in Mainland China', Asian Studies Review. (DOI: http://dx.doi.org/10.1080/10357823.2017.1294145). Author Copy.

Yong, Jie (2009) 2009 nian ci yue shijui ri Jing Boran BBF jijin zhengshi chengli [19.4.2009, the Jing Boran BBF Fund is established]. Blog, 22 April. Available at http://blog.sina.com.cn/s/blog_54c0752f0100cy2g.html, accessed 3 March 2016.

You ai jiu you xiwang. You xiwang jiu buyao fangqi [There is love, there is hope. Don't give up] (2012) Tieba. Available at http://tieba.baidu.com/p/1396760584?pn=1, accessed 3 March 2016.

Yumi aixin jijin beijing [Background: Li Yuchun Fan Charity Fund] (2007) Chinese Red Cross Foundation, 17 August. Available at http://www.crcf.org.cn/sys/html/lm_57/2007-0817/175209.htm, accessed 3 March 2016.

Yumi aixin jijin jianjie [Li Yuchun Fan Charity Fund introduction] (2008) Tieba, 30 April. Available at http://tieba.baidu.com/p/1024991312, accessed 3 March 2016.

Yumi aixin jijin [Li Yuchun Fan Charity Fund] (2011) Zhongguo Yulewang, 1 August. Available at http://news.67.com/cishanquan/2011/08/01/279827.html, accessed 3 March 2016.

Yumi gongyi jianxun [Li Yuchun fans philanthropy brief] (2014) Lee Zhoukan, 29 December. Available at http://www.leeweekly.com/?p=10414, accessed 3 March 2016.

Yumi yigong xianjie jieshao-201103 ban [Detailed introduction to the Li Yuchun Fan Charity Fund, March 2011 Edition] (2011) Tieba, March 14. Available at http://tieba.baidu.com/p/1024991312, accessed 3 March 2016.

Zhangjie beidouxingkong zhiyuan cishanhui [Zhang Jie Big Dipper Volunteers' Charity] (2015) Baidu Baike. Available at http://baike.baidu.com/view/2693174.htm, accessed 3 March 2016.

Zhang Jie beidouxingkong zhiyuan cishanhui jishi [Chronicle of the Zhang Jie Big Dipper Volunteers' Charity] (n.d.) Zhang Jie - Beidouxingkong Zhiyuancishanhui, 10 September. Available at http://blog.sina.com.cn/hearjason, accessed 3 March 2016. 
Elaine Jeffreys and Jian XU (2017) 'Celebrity-inspired, Fan-driven: Doing Philanthropy through Social Media in Mainland China', Asian Studies Review. (DOI: http://dx.doi.org/10.1080/10357823.2017.1294145). Author Copy.

Zhang Jie "juankuanmen" bao fensi tuan heimu: fentou yue ruguo wan [Zhang Jie "donationgate" exposé: "head fan" makes thousands] (2012) Hualongwang, 22 May. Available at http://www.taiwan.cn/yl/mxsj/201205/t20120522_2690039.htm, accessed 3 March 2016.

Zhang Jie yinyue mengxiang jiaoshi [Zhang Jie music dream classroom] (2015) Baidu Baike. Available at http://baike.baidu.com/view/10348534.htm, accessed 3 March 2016.

Zhang, Ning (2014) Web-based backpacking communities and online activism in China: Movement without marching. China Information, 28(2), pp. 276-96.

Zhang, Ting (2012) Ji Minjia bei pin wei Hubei xiwang gongcheng aixin dashi [Ji Minjia becomes a goodwill ambassador for Project Hope in Hubei]. Zhongguo Qingnianwang, 5 August. Available at http://qnzz.youth.cn/wdqcwdt/cszz/201207/t20120705_2251746.htm, accessed 3 March 2016.

Zhang, Weiyu and Mao, Chengting (2013) Fan activism sustained and challenged: Participatory culture in Chinese online translation communities. Chinese Journal of Communication 61, pp. 45-61. 